\title{
Posterior Parietal Cortex Dysfunction Is Central to Working Memory Storage and Broad Cognitive Deficits in Schizophrenia
}

\author{
Britta Hahn, ${ }^{1}$ Benjamin M. Robinson, ${ }^{1}$ Carly J. Leonard, ${ }^{2}$ Steven J. Luck, ${ }^{3}$ and James M. Gold ${ }^{1}$ \\ ${ }^{1}$ Maryland Psychiatric Research Center, University of Maryland School of Medicine, Baltimore, Maryland 21228, ${ }^{2}$ Department of Psychology, University of \\ Colorado, Denver, Colorado 80204, and ${ }^{3}$ Center for Mind and Brain, University of California-Davis, Davis, California 95618
}

PFC dysfunction is widely believed to underlie working memory (WM) deficits in people with schizophrenia (PSZ), but few studies have focused on measures of WM storage devoid of manipulation. Research in neurotypical individuals has shown that storage capacity is more closely related to posterior parietal cortex (PPC) than PFC, suggesting that reductions in WM storage capacity in schizophrenia that are associated with broad cognitive deficits may be related to neural activity in PPC. In the present human neuroimaging study, 37 PSZ and 37 matched healthy control subjects of either sex completed a change detection task with varying set sizes while undergoing fMRI. The task was designed to emphasize WM storage with minimal top-down control demands. Whole-brain analysis identified areas in which BOLD activity covaried with the number of items maintained in WM $(K)$, as derived from task performance at a given set size. Across groups, $K$ values independent of set size predicted BOLD activity in PPC, including superior and inferior parietal lobules and intraparietal sulcus, and middle occipital gyrus. Whole-brain interaction analysis found significantly less $K$-dependent signal modulation in PSZ than healthy control subjects in left PPC, a phenomenon that could not be explained by a narrower $K$ value range. The slope between $K$ and PPC activation statistically accounted for $43.4 \%$ of the between-group differences in broad cognitive function. These results indicate that PPC dysfunction is central to WM storage deficits in PSZ and may play a key role in the broad cognitive deficits associated with schizophrenia.

Key words: cognition; fMRI; posterior parietal cortex; schizophrenia; working memory

Significance Statement

People with schizophrenia exhibit cognitive deficits across a wide range of tasks. Explaining these impairments in terms of a small number of core deficits with clearly defined neural correlates would advance the understanding of the disorder and promote treatment development. We show that a substantial portion of broad cognitive deficits in schizophrenia can be explained by a failure to flexibly modulate posterior parietal cortex activity as a function of the amount of information currently stored in working memory. Working memory deficits have long been considered central to schizophrenia-related cognitive deficits, but the focus has been on paradigms involving some form of top-down control rather than pure storage of information, which may have unduly narrowed the focus on prefrontal dysfunction.

\section{Introduction}

Working memory (WM) impairments are considered a central aspect of the cognitive deficits associated with schizophrenia (Lee

Received April 9, 2018; revised July 9, 2018; accepted Aug. 6, 2018.

Author contributions: B.H. wrote the first draft of the paper; B.H., C.J.L., S.J.L., and J.M.G. edited the paper; B.H., C.J.L., S.J.L., and J.M.G. designed research; B.M.R. performed research; B.H. analyzed data; B.H. wrote the paper.

This work was supported by NIH grant R01 MH065034 to J.M.G. and S.J.L. We thank Abigail Ruffle for help with data acquisition; Dr. Shuo Chen for statistical advice; Sharon August and Leeka Hubzin for performing neuropsychological assessments; and all participants for volunteering time for this study.

The authors declare no competing financial interests.

Correspondence should be addressed to Dr. Britta Hahn, University of Maryland School of Medicine, Maryland Psychiatric Research Center, P.0. Box 21247, Baltimore, MD 21228. E-mail: bhahn@som.umaryland.edu.

DOI:10.1523/JNEUROSCI.0913-18.2018

Copyright $\odot 2018$ the authors $\quad 0270-6474 / 18 / 388378-10 \$ 15.00 / 0$ and Park, 2005). However, WM is a heterogeneous construct (Baddeley, 2007; Shura et al., 2016) that involves both short-term information storage, and active manipulation, prioritization, and rehearsal of the stored material (Engle et al., 1999; Cowan, 2017). Most functional neuroimaging paradigms investigating the underpinnings of WM deficits in schizophrenia involved manipulation of the stored material or allowed for active rehearsal, thus combining storage and executive control aspects of WM (Barch et al., 2012). The majority of these studies identified abnormalities in PFC recruitment in participants with schizophrenia (PSZ) (e.g., Manoach, 2003; Glahn et al., 2005; Van Snellenberg et al., 2006).

Basic cognitive neuroscience studies suggest that these PFC abnormalities may reflect impaired executive control processes of 
$\mathrm{WM}$, rather than WM storage. In healthy individuals, the role of PFC in executive control functions is well established; indeed, these functions have been suggested to explain most reports of persistent PFC activity during retention in delayed-response tasks (Curtis and D'Esposito, 2003; Postle, 2006; Serences, 2016). Individual differences in PFC recruitment sometimes predict WM storage capacity, but this appears to reflect the operation of top-down control processes over storage resources ( $\mathrm{McNab}$ and Klingberg, 2008; Edin et al., 2009; Minamoto et al., 2015). In contrast, intraparietal sulcus (IPS) and occipital activity patterns more closely predict storage capacity constraints per se (Postle et al., 2006; Xu and Chun, 2006; Linden, 2007; McNab and Klingberg, 2008; Edin et al., 2009). Regardless of the debate over whether posterior parietal cortex (PPC) functions mediate item representations themselves or the maintenance of attention over items whose features are represented in sensory cortex (Postle, 2006; Xu and Chun, 2006; Mitchell and Cusack, 2008; Emrich et al., 2013; Xu, 2017), there is strong evidence that PPC-based functions are central to WM storage.

In recent years, evidence has accumulated that pure indices of storage capacity (the number of representations that can be maintained simultaneously in WM) are substantially reduced in PSZ relative to healthy control subjects (HCS) (e.g., Gold et al., 2010; Erickson et al., 2015). WM storage capacity predicted global cognitive abilities in both PSZ and HCS, accounting for $\sim 40 \%$ of the between-group variance in measures of intelligence and cognitive domains relevant to schizophrenia (Johnson et al., 2013). These findings were based on visual change detection tasks, which emphasize WM storage processes (i.e., encoding and maintenance of the material but not its manipulation), and are not conducive to verbal rehearsal strategies (Luck and Vogel, 1997; Vogel et al., 2001). A varying number of objects is presented briefly (100-200 ms), followed by a short retention interval, and then a test array. Participants report whether the test array is identical to the sample array or one item has changed.

Using this paradigm, basic cognitive neuroscience confirmed the PPC as a key determinant of WM storage capacity. fMRI studies found that activation of IPS and intraoccipital sulci, but not PFC, was related to the number of items actually maintained in WM (Todd and Marois, 2004) and to individual differences in WM capacity (Todd and Marois, 2005). These results are mirrored by sustained event-related potentials (ERPs) that appear to arise from PPC (Robitaille et al., 2009), whose magnitude is related to the number of items maintained in WM and asymptotes at an individual's storage capacity (Vogel and Machizawa, 2004). This ERP effect is reduced in PSZ (Leonard et al., 2013). fMRI studies using various cognitive tasks frequently identified PPC as part of larger network abnormalities in schizophrenia; however, PPC dysfunction has never been considered a central component (e.g., Ragland et al., 2009; Barch and Ceaser, 2012).

The present study aimed at pinpointing the neuroanatomical correlates of WM storage capacity reductions in schizophrenia, hypothesizing that PPC would play a central role.

\section{Materials and Methods}

Subjects. Forty outpatients meeting Diagnostic and Statistical Manual of Mental Disorders-IV (DSM-IV) ${ }^{41}$ criteria for schizophrenia or schizoaffective disorder $(N=7)$, and 38 HCS completed this study. Diagnosis was established using a best estimate approach combining information from a Structured Clinical Interview for DSM-IV (SCID) with a review of medical records. Data from 1 HCS and 3 PSZ were excluded from analyses due to excessive head motion (criteria specified below), resulting in $N=37$ per group. Table 1 summarizes the demographic characteristics
Table 1. Participant demographics

\begin{tabular}{|c|c|c|c|}
\hline & PSZ $(N=37)$ & $\mathrm{HCS}(N=37)$ & Statistics \\
\hline Age (yr) & $\begin{array}{c}36.3 \pm 11.2 \\
\text { (range 19-55) }\end{array}$ & $\begin{array}{c}37.0 \pm 11.7 \\
\text { (range 21-55) }\end{array}$ & $\begin{array}{l}t_{(72)}=0.25 \\
p=0.8\end{array}$ \\
\hline Male/female & $23: 14$ & $23: 14$ & $\begin{array}{l}\chi^{2}=0 \\
p=1\end{array}$ \\
\hline Black/white/other & $12: 21: 4$ & $14: 23: 0$ & $\begin{array}{l}\chi^{2}=4.25 \\
p=0.12\end{array}$ \\
\hline Education (yr) & $12.8 \pm 2.1$ & $15.5 \pm 1.9$ & $\begin{array}{l}t_{(72)}=5.71 \\
p<0.001\end{array}$ \\
\hline Parental education (yr) $^{a}$ & $13.5 \pm 2.7$ & $14.7 \pm 2.6$ & $\begin{array}{l}t_{(72)}=1.89 \\
p=0.062\end{array}$ \\
\hline Estimated $I Q^{b, f}$ & $99.5 \pm 14.8$ & $115.9 \pm 8.8$ & $\begin{array}{l}t_{(68)}=5.54 \\
p<0.001\end{array}$ \\
\hline $\mathrm{MCCB}^{c, f}$ & $37.1 \pm 12.9$ & $53.6 \pm 7.8$ & $\begin{array}{l}t_{(68)}=6.39 \\
p<0.001\end{array}$ \\
\hline WRAT $4^{d, f}$ & $98.6 \pm 17.0$ & $115.1 \pm 13.0$ & $\begin{array}{l}t_{(68)}=4.53 \\
p<0.001\end{array}$ \\
\hline $\mathrm{WTAR}^{e, f}$ & $100.2 \pm 18.2$ & $115.8 \pm 7.1$ & $\begin{array}{l}t_{(68)}=4.61 \\
p<0.001\end{array}$ \\
\hline
\end{tabular}

${ }^{a}$ Average over maternal and paternal education.

${ }^{b}$ Based on the Wechsler Abbreviated Scale of Intelligence-II (Wechsler, 2011).

'Composite score on the MATRICS Consensus Cognitive Battery (Nuechterlein and Green, 2006).

${ }^{d}$ Wide Range Achievement Test (Wilkinson and Robertson, 2006).

${ }^{e}$ Wechsler Test of Adult Reading (Wechsler, 2001).

Data missing for $4 \mathrm{HCS}$.

of these participants. Groups did not differ in age, sex, or ethnicity, but PSZ had fewer years of education and scored lower than HCS on neuropsychological tests of cognitive functioning, including the MATRICS Consensus Cognitive Battery (MCCB) designed to provide an evaluation of key cognitive domains impaired in schizophrenia (Wechsler, 2001, 2011; Nuechterlein and Green, 2006; Wilkinson and Robertson, 2006). There was a trend toward lower parental education in PSZ than in HCS, but we found no significant or trend correlations between parental education and any of the main dependent variables, so this modest and nonsignificant difference cannot explain the results presented below.

PSZ were stably medicated outpatients with a total score of $30.1 \pm 7.1$ (mean \pm SD) on the Brief Psychiatric Rating Scale (range 21-47) (Overall and Gorman, 1962), $22.7 \pm 13.0$ on the Scale for the Assessment of Negative Symptoms (range 2-58) (Andreasen, 1984), $17.5 \pm 12.4$ on the Brief Negative Symptom Scale (range 0-65) (Kirkpatrick et al., 2011), $22.4 \pm 6.5$ on the Level Of Functioning Scale (range 6-36) (Hawk et al., 1975), and an average overall global rating of $3.0 \pm 0.8$ on the Multidimensional Scale of Independent Functioning (range 2-5) (Jaeger et al., 2003). All PSZ were receiving antipsychotic medication: 28 secondgeneration antipsychotics, 4 first-generation antipsychotics, and 5 both. Sixteen PSZ additionally received antidepressant medication, 5 mood stabilizers, 13 anxiolytic, and 7 antiparkinsonian medications. One patient was taking methylphenidate and another varenicline. Medication and dosages had not changed in the preceding 4 weeks. Drug or alcohol abuse within the last 6 months was exclusionary for both PSZ and HCS, as verified by targeted screening questions, chart review (if available), the SCID, and urine and breathalyzer tests. Color blindness, as tested with the Ishihara plates, was also exclusionary. HCS were recruited via online advertising, flyers, and word of mouth. HCS had no Axis 1 or 2 diagnoses as established by a SCID, had no self-reported family history of psychosis, and were not taking any psychotropic medication, with the exception of 1 participant, who was taking carbamazepine as a muscle relaxant. Participants provided informed consent for a protocol approved by the Institutional Review Board of the University of Maryland Baltimore. Before PSZ signed the consent form, the investigator, in the presence of a witness, formally evaluated basic understanding of study demands, risks, and what to do if experiencing distress or to end participation. All participants were paid for their time.

Procedure. Participants were consented and screened on a separate day preceding the MR scan. They were instructed not to consume any caffeine on 


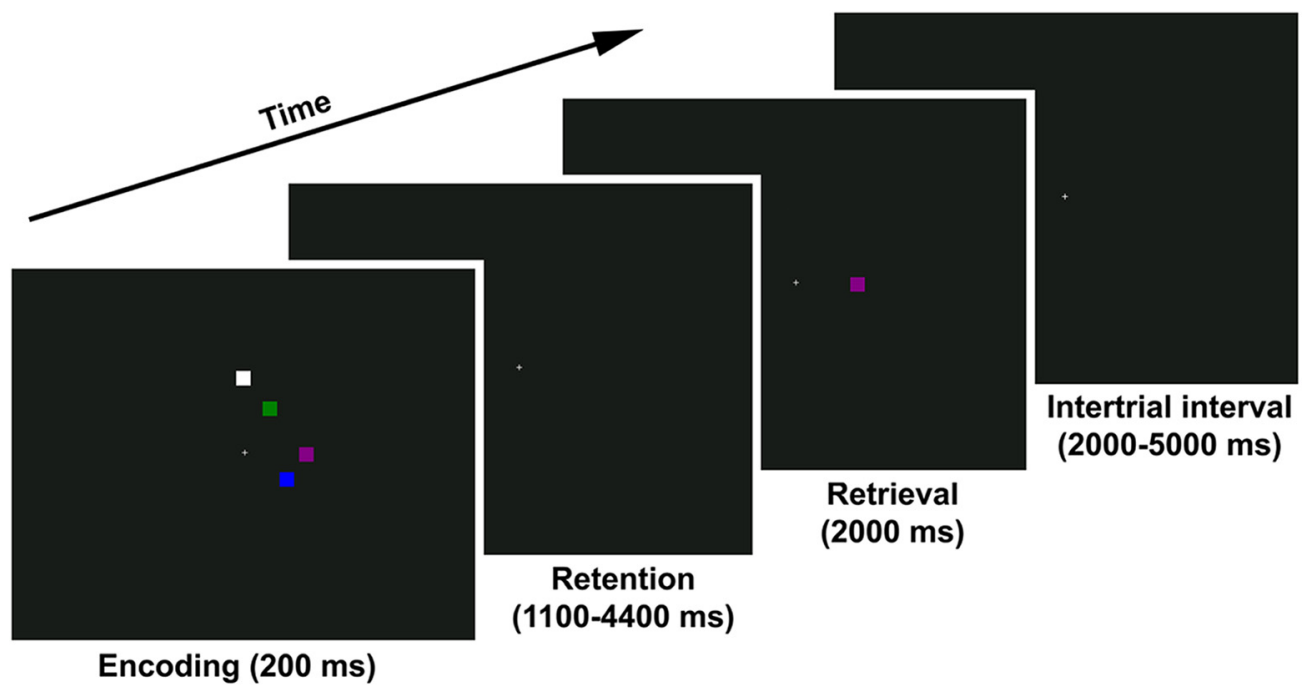

Figure 1. Change detection task. Each encoding array contained 1,2,4,6, or 7 items. The task was to report whether the test item was the same color as the corresponding item from the encoding array or had changed to a new color. Shown here is a no-change trial at set size 4.

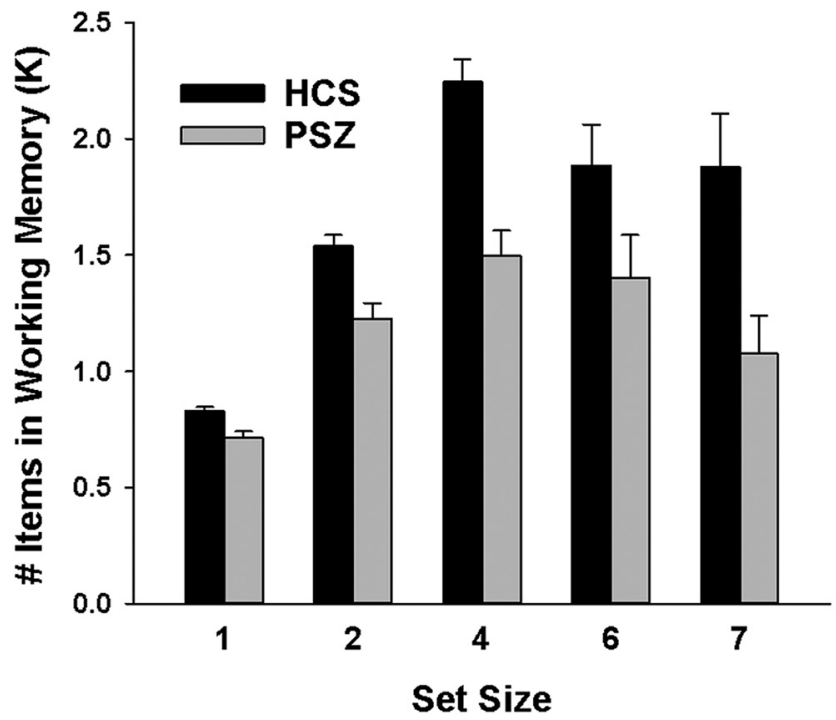

Figure 2. Task performance. Mean ( \pm SEM) number of items stored in working memory $(K)$ in people with schizophrenia (PSZ) and healthy control subjects (HCS).

Table 2. Clusters identified as displaying linear activation change with items maintained in working memory $(K)^{a}$

\begin{tabular}{|c|c|c|c|c|c|}
\hline \multirow[b]{2}{*}{ Region } & \multirow[b]{2}{*}{ Side } & \multirow[b]{2}{*}{ Volume ( $\mu \mathrm{l})$} & \multicolumn{3}{|c|}{ Center of mass (mm) } \\
\hline & & & $L R$ & PA & IS \\
\hline $\begin{array}{l}\text { Superior and inferior parietal lobule, } \\
\text { precuneus, middle occipital gyrus }\end{array}$ & $\mathrm{R}$ & 11718 & 27.5 & -60.2 & 42.6 \\
\hline $\begin{array}{l}\text { Superior and inferior parietal } \\
\text { lobule, precuneus }\end{array}$ & L & 7991 & -24.8 & -61.7 & 46.6 \\
\hline Middle occipital gyrus & $\mathrm{L}$ & 2430 & -27.8 & -76.8 & 19.2 \\
\hline
\end{tabular}

$\mathrm{LR}=$ left-right; $\mathrm{PA}=$ posterior-anterior; $\mathrm{IS}=$ inferior-superior.

the day of the scan. On the day of the scan, participants received task instructions and performed a short practice version of the change detection task on a desktop computer. The change detection task was then performed in the scanner. An anatomical scan was obtained after the first 4 task blocks. Neuropsychological testing and psychiatric ratings were completed on a separate day. Neuropsychological tests of cognitive functioning were completed within 6 months of the scan session (mean \pm SD, $55.8 \pm 51.6 \mathrm{~d}$ ) for all, except 6 of the 74 participants (all PSZ), for whom we used test scores obtained as part of a previous study (276 to $608 \mathrm{~d}$ prescan) because of scheduling problems. This was deemed appropriate because of the demonstrated temporal stability of neuropsychological measures of cognition in PSZ (Heaton et al., 2001). Psychiatric ratings were obtained within 3 months of the $\operatorname{scan}(34.7 \pm 30.0 \mathrm{~d})$.

Task paradigm. The paradigm was first described by Luck and Vogel (1997). Participants viewed a $200 \mathrm{~ms}$ encoding array of $1,2,4,6$, or 7 squares $\left(\sim 1 \times 1^{\circ}\right.$ of visual angle) on a black background (Fig. 1$)$. Each square was painted in a different color chosen at random from a pool of red, magenta, purple, blue, teal, cyan, green, olive, yellow, and white. Verbal rehearsal strategies were impeded by the brief encoding period and the fact that most of the colors cannot be quickly coded in easily namable categories. After a blank-screen delay of variable duration $(1100,1650,2200,2750,3300,3850$ or $4400 \mathrm{~ms})$, one of the squares from the encoding array reappeared for $2000 \mathrm{~ms}$ at its original location. The task was to make an index finger response if the color of this test item had changed relative to the original presentation, and a middle finger response if the color stayed the same (50\% probability). When the color changed, the new color was selected at random from the colors that were not present in the original encoding array.

Trials were separated by a variable intertrial interval $(2000,2500,3000$, $3500,4000,4500$, or 5000$)$. A white fixation cross $\left(\sim 0.66 \times 0.66^{\circ}\right.$ of visual angle) stayed at the center of the display throughout the task. It served as a spatial reference point; participants were not explicitly instructed to keep their eyes fixated on the cross. The task was presented in eight 4:56 min runs of 35 trials each, with 7 trials of each set size presented in random order in each run. After each run, the scanner turned off and the experimenter checked in on the participant via intercom (the participant responded by button press). Total task length was $\sim 45 \mathrm{~min}$.

When examining neural activity related to WM storage, it is essential to distinguish between activity related to the storage of information, and activity related to task difficulty, display complexity, etc. To emphasize actual WM storage over task demands, we focused our analyses on the number of items actually stored in WM for a given set size, denoted $K$, which was derived from performance as described below. As set size increases, $K$ increases, plateaus close to an individual's WM capacity $\left(K_{\max }\right)$, and then declines with even larger set sizes as a subportion of the array must be selected for encoding. This creates an inverted U-shaped dose-response curve of $K$ in relation to set size, with different factors influencing the ascending arm (small number of items available for storage), the descending arm (selection demands), and the peak section of this curve $\left(K_{\max }\right)$. Thus, any BOLD activity identified as being linearly related to $K$ cannot be explained by any of these factors. $K$-related signal has a different relationship to set size than task difficulty or selection 


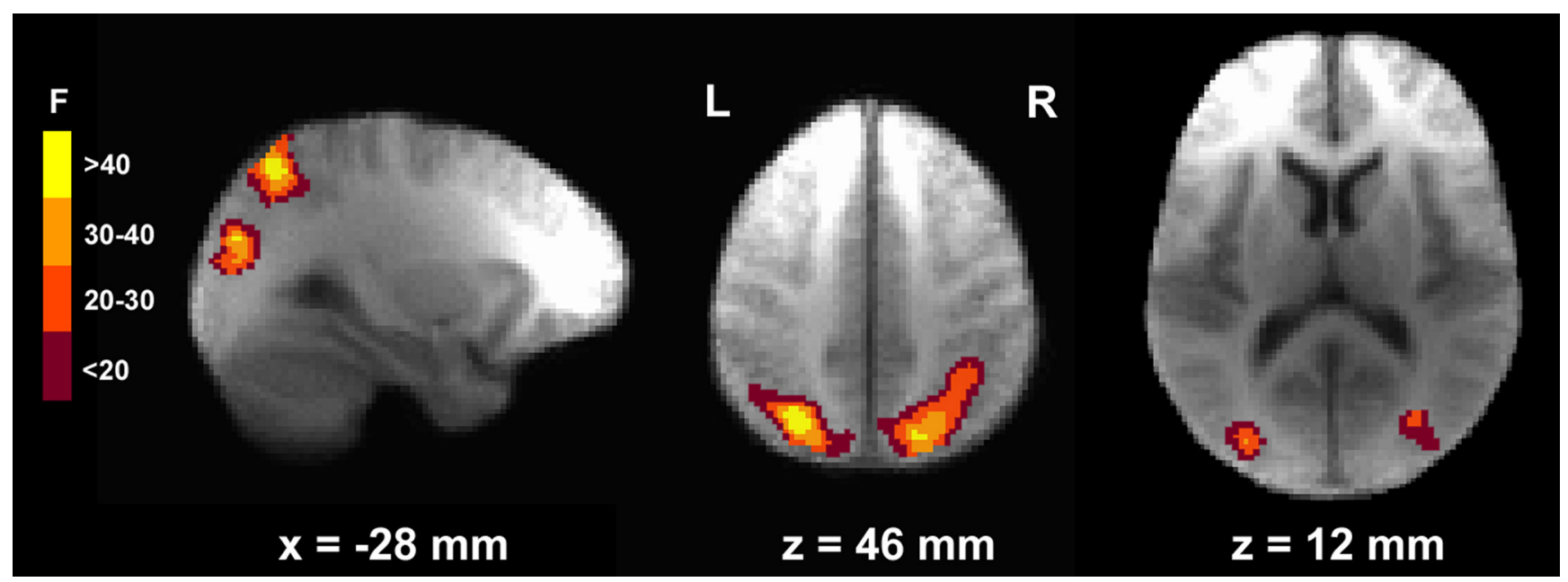

Figure 3. Regions associated with WM storage as identified by K regressor. Shown here are clusters of voxels that displayed a significant linear signal change with the number of items maintained in working memory $(K)$, independent of set size. Group activation maps are overlaid onto anatomical scans in Talairach space, averaged over all 74 participants.

demands, which grow with increasing set size even beyond the individual's WM capacity. Under the present task conditions, $K$-related variance provides a relatively pure reflection of the number of simultaneously active representations (Lin and Luck, 2012), with relatively little influence of executive processes that contribute to performance indices on most other WM tasks (Kane and Engle, 2000; Lustig et al., 2001).

Because $K$-related signal reflects actual WM storage, and not demands defined by the task, using $K$ as the regressor of interest effectively eliminates confounds related to group differences in task performance. In other words, our regression approach identified clusters of voxels whose BOLD signal varied linearly with participants' behaviorally measured $K$, as in the previous fMRI studies (Todd and Marois, 2004, 2005). The inclusion of set size as a regressor of no interest ensured that all identified signal reflected $K$ independent of set size.

MRI. A 3-tesla Tim Trio scanner (Siemens) acquired whole-brain EPI images for measuring $\mathrm{T} 2^{*}$-weighted BOLD effects $\left(4 \mathrm{~mm}\right.$ oblique $\left[13.5^{\circ}\right]$ axial slices, $128 \times 128$ matrix, FOV $=22 \times 22 \mathrm{~cm}, \mathrm{TR}=2 \mathrm{~s}, \mathrm{TE}=27 \mathrm{~ms}$, $\mathrm{FA}=90^{\circ}$ ). An axial T1-weighted image (MPRAGE) provided anatomical reference $\left(0.8 \mathrm{~mm}^{3}\right.$ voxels, $\left.\mathrm{TR}=2.2 \mathrm{~s}, \mathrm{TE}=2.83 \mathrm{~ms}, \mathrm{FA}=13^{\circ}\right)$.

Data were processed using AFNI (Cox, 1996). Each volume was registered to a base volume. For each subject, a composite motion index was calculated from the six motion correction parameters (Yang et al., 2005). These scores did not differ between HCS and PSZ $\left(t_{(72)}=1.10, p>0.27\right)$. TRs with $>0.5 \mathrm{~mm}$ displacement or $>0.5^{\circ}$ rotation relative to the preceding TR were censored out of the time series. Participants with $>304$ $(25 \%)$ censored TRs were excluded from analyses. This applied to 1 HCS and 3 PSZ (see Subjects). The number of censored TRs did not differ between groups $\left(t_{(72)}=0.02, p>0.9\right)$.

First-level analysis. The time series was analyzed as an event-related design by voxelwise multiple regression. Regressors were expressed as a delta function, time-locked to the onset of each encoding array, convolved with a model hemodynamic response function and its temporal derivative. Regressors corresponded to the five set sizes (1, 2, 4, 6, and 7). Of note, very similar results were obtained when the time series was analyzed as a duration-modulated block design using the dmBLOCK option in AFNI, with duration reflecting the length of the retention interval on each trial. Regressors of no interest corresponded to the onset of the retrieval array, and to the onset of the encoding and retrieval array on trials in which the participant did not respond or responded prematurely. Furthermore, the six motion parameter curves were included as regressors of no interest. Pearson correlations were calculated for each subject between the time course of the signal related to each of the five regressors of interest and each of the six motion regressors. All 2220 correlations were $R<0.155$, only 12 were significant when uncorrected, and none survived correction for multiple comparisons. The two diagnostic groups did not differ in the average correlation between stimulus- related signal and motion $\left(t_{(72)}=0.075, p>0.9\right)$. For each subject, the voxelwise average amplitude of signal change produced by each of the five set sizes was determined. These maps were resampled to a $1 \mu \mathrm{l}$ resolution, converted to a standard coordinate system (Talairaque and Tournoux, 1988), and spatially blurred using a Gaussian $5 \mathrm{~mm}$ root mean square isotropic kernel.

Second-level analyses. Whole-brain voxelwise multiple linear regression was performed on the 370 maps (one map for each set size for each of the 74 subjects). The first analysis was designed to define regions whose signal was related to current WM storage regardless of diagnostic group membership. In this analysis, $K$, as derived from performance (see below), was the regressor of interest. Group (HCS, PSZ), the group $\times K$ interaction, set size $(1,2,4,6,7)$, and subject were included in the model as regressors of no interest. Voxelwise $p<0.001$ combined with a $946 \mu \mathrm{l}$ clustersize threshold yielded overall $p<0.05$ based on Monte Carlo simulations. A second whole-brain analysis was designed to find regions in which $K$-related activity differed between groups (i.e., areas in which the function relating $K$ to BOLD activity differed between PSZ and HCS). In this analysis, the group $\times K$ interaction was the regressor of interest, with $K$, group, set size, and subject included in the statistical model as regressors of no interest. Voxelwise $p<0.001$ combined with a $466 \mu \mathrm{l}$ clustersize threshold yielded overall $p<0.05$, again based on Monte Carlo simulations. For each subject, BOLD activity was averaged within each of the resulting clusters at each set size.

Experimental design and statistical analysis. The formula used to convert performance into an estimate of $K$ was derived by Cowan (2001) and has been validated as the model of choice for single-probe change detection tasks, such as used in the present study (Rouder et al., 2011):

$$
K=\text { set size } *(\text { hit rate }- \text { false alarm rate })
$$

According to this formula, complete guessing in the absence of any WM representation would result in a $K$ estimate of 0 . At the smaller set sizes ( 1 and 2), $K$ is mostly limited by the number of items presented, whereas at larger set sizes, $K$ is limited by an individual's working memory capacity. At set sizes that far exceed capacity ( 6 and 7 ), $K$ is also impacted by the individual's ability to select a subset of items for storage. By using $K$ across a wide range of set sizes as the regressor of interest, we extract brain signal reflective of the number of items currently stored, regardless of the different factors that may contribute to the variance therein.

$K$ was analyzed by 2 -factor ANOVA for repeated measures, with diagnostic group as a between-subject factor and set size as a within-subject factor. A secondary performance index was the percentage of trials in which no response was made. Reaction times were not recorded.

For the brain region identified as displaying a $K \times$ group interaction (see below) i.e., a relationship between performance-based $K$ values and 


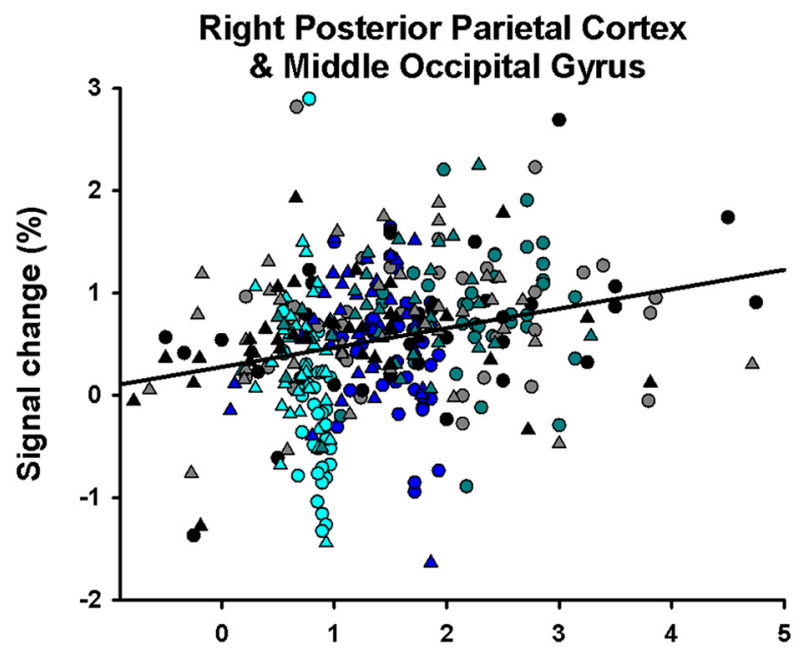

Left Posterior Parietal Cortex
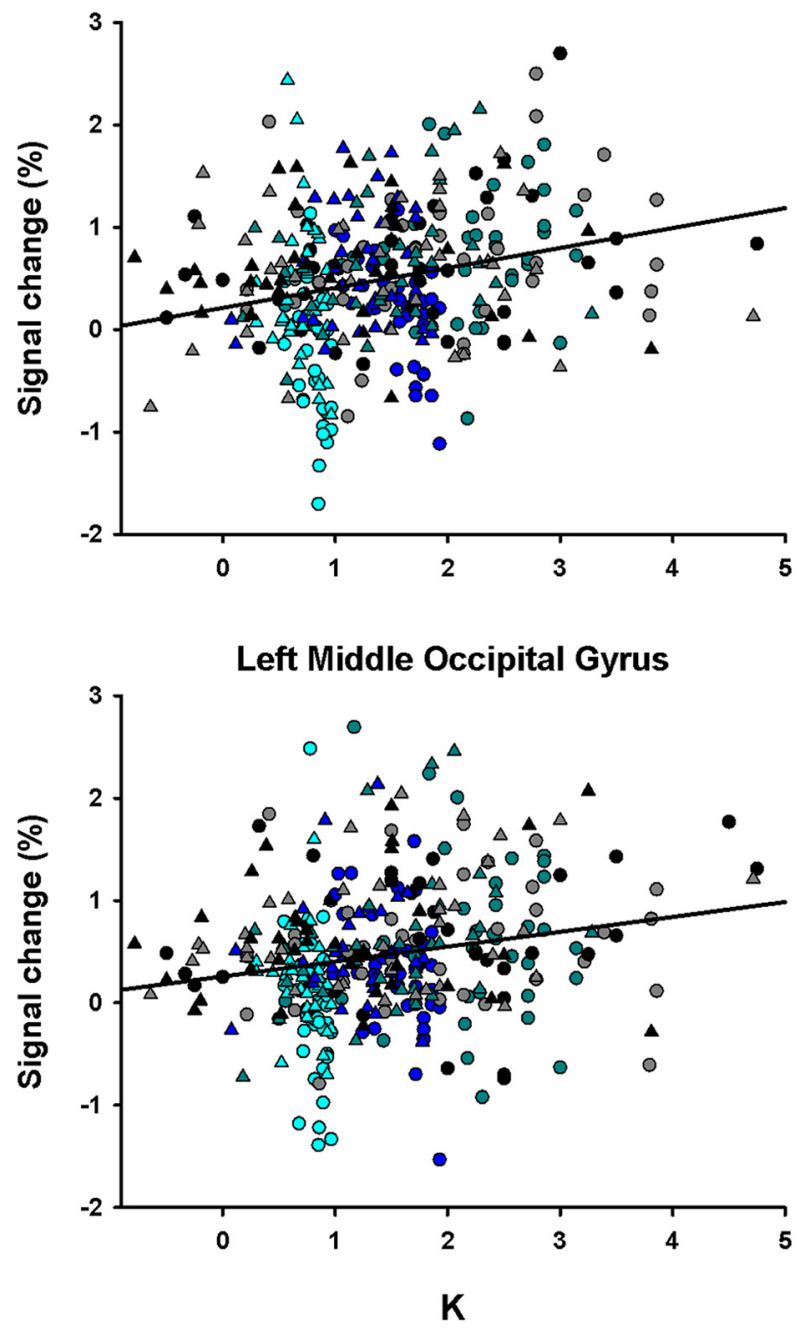

O HCS - SS1
HCS - SS2
O HCS - SS4
O HCS - SS6
- HCS - SS7

$\triangle P S Z$ - SS1

PSZ - SS2

$\triangle P S Z$ - SS4

$\triangle$ PSZ - SS6

$\triangle$ PSZ - SS7

Figure 4. K-dependent activation change. Scatter plots represent the relationship between $K$ and activation in the three clusters displayed in Figure 3 and listed in Table 2. Each healthy control subject (HCS; circle) and each participant with schizophrenia (PSZ; triangles) contribute five data points to each graph, one at each set size.
Table 3. Cluster displaying a different linear activation change with $K$ in HCS and PSZ (identified as a $K \times$ group interaction)

\begin{tabular}{lllllll}
\hline \multirow{2}{*}{ Region } & & \multicolumn{3}{l}{ Center of mass $(\mathrm{mm})$} \\
\cline { 5 - 6 } & Side & Volume $(\mu \mathrm{l})$ & LR & PA & IS \\
\hline Superior and inferior parietal lobule & $\mathrm{L}$ & 1941 & 23.7 & 61.8 & 45.9 \\
\hline
\end{tabular}

BOLD signal that differed between diagnostic groups, each participant's regional average BOLD activity at each set size was paired with $K$ at this set size, and the five BOLD-K pairs were entered into a linear regression model $(\mathrm{BOLD}=a+b \times K)$ to obtain the slope, $b$, of the relationship between $K$ and BOLD signal for each individual participant. This is a measure of the extent to which the BOLD activity in that area changes with the amount of information actually stored in WM. Because of nonnormality of the slope coefficient distribution, all statistical analyses involving slope used nonparametric tests: one-sample Wilcoxon signed rank tests for comparisons against zero, Mann-Whitney $U$ tests for group comparisons, and Spearman rho correlations to test associations with cognitive measures. The same pattern of results was obtained when using parametric tests.

\section{Results}

Behavioral task performance

Figure 2 displays the number of items stored in WM $(K)$ as a function of set size in HCS and PSZ. Both groups displayed the expected inverted U-shaped dose-response function, with both HCS and PSZ storing the most items at set size 4 (main effect of set size: $\left.F_{(4,288)}=27.9, p<0.001\right)$. Overall, $K$ was reduced in PSZ relative to HCS, as supported by a main effect of group $\left(F_{(1,72)}=\right.$ $535.5, p<0.001)$. This difference was especially pronounced at the three larger set sizes, resulting in an overall flattened curve in PSZ (group $\times$ set size interaction: $F_{(4,288)}=3.47, p=0.009$ ).

No-response trials were rare overall. They did not vary with set size $\left(F_{(4,288)}=1.15, p=0.335\right)$, and there was no set size $\times$ group interaction $\left(F_{(4,288)}=0.72, p=0.580\right)$. However, noresponse trials tended to be more numerous in PSZ $(3.3 \pm 4.2 \%)$ than in HCS $(1.6 \pm 2.7 \%)$, as supported by a main effect of group $\left(F_{(1,72)}=4.62 ; p=0.035\right)$.

\section{MRI}

$\mathrm{K}$ main effect

As a first step, we sought to test whether PPC was indeed central to WM storage processes, as indicated by previous studies. Three clusters were identified as displaying linear activation change with $K$ across groups (Table 2; Fig. 3). The largest cluster, on the right, spanned multiple PPC regions, including superior and inferior parietal lobule (SPL, IPL) and IPS, as well as the middle occipital gyrus. Symmetrical left PPC and middle occipital gyrus regions were identified in two separate clusters. All three clusters were more activated with more items maintained in WM (Fig. 4). These regions are similar to $K$-related clusters identified in previous change detection research with healthy young adults (Todd and Marois, 2004, 2005).

\section{$\mathrm{K} \times$ group interaction}

A single cluster, located in left PPC and including SPL, IPL, and IPS, was identified as showing a $K \times$ group interaction (Table 3; Fig. 5). Ninety-four percent of this region overlapped with the left PPC region described above, identified as displaying a $K$ main effect. In HCS, but not in PSZ, activation of this region increased with more items maintained in WM (Fig. 6). The average slope of this association in HCS was significantly larger than zero $(Z=-4.34, p<$ 0.001). In PSZ slope did not differ from zero $(Z=-1.49, p=0.14)$ and was significantly smaller than in $\operatorname{HCS}(U=364.5, p<0.001)$. 


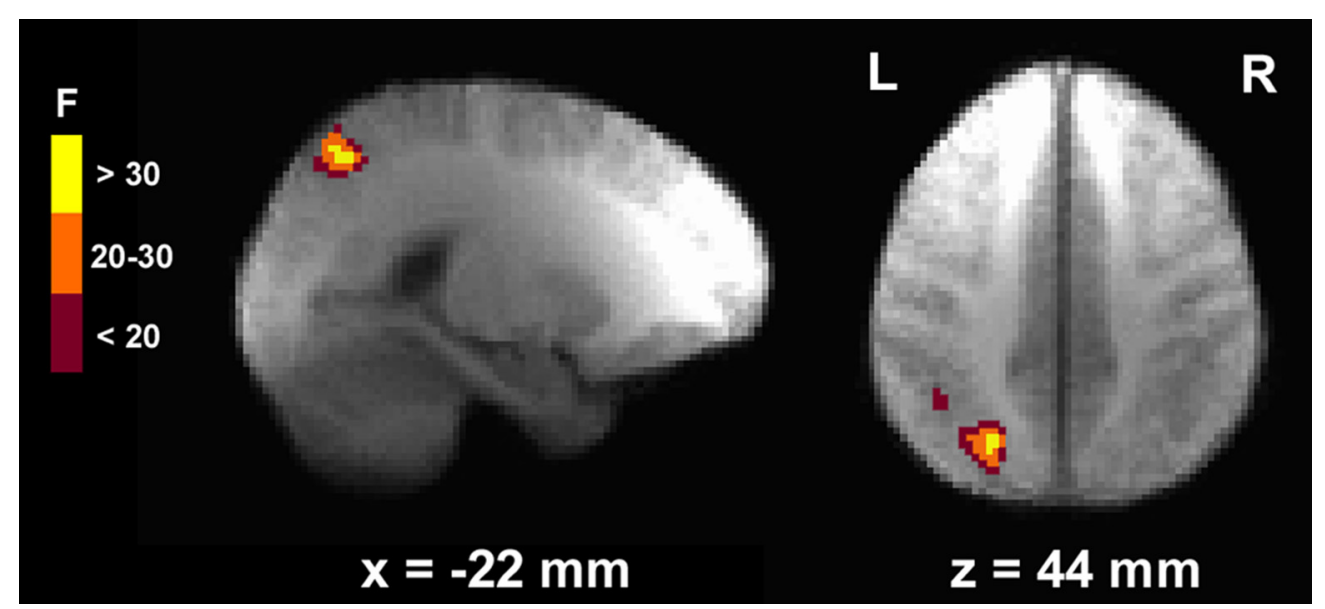

Figure 5. Region identified by the $K \times$ group interaction regressor. The left posterior parietal cortex (PPC) region shown here displays differential $K$-dependent signal change in healthy control subjects versus participants with schizophrenia. Group activation maps are overlaid onto anatomical scans in Talairach space, averaged over all participants.

To test whether the lack of $K$-dependent modulation of this region in PSZ could be explained by the more limited range of $K$ values in PSZ compared with HCS, we recalculated slope values for all participants based only on $K$-BOLD data pairs with $K \leq 2$. Because $K$ at set sizes 1 and 2 was always $\leq 2$, all participants had at least two data pairs meeting this criterion, but most participants (64 of 74) had at least three. While the variance of $K$ values differed significantly between groups in the full dataset $(F=5.41$, $p<0.021$, Levene's test), the variance no longer differed between groups in this subset of data pairs $(F=0.67, p=0.415)$. Slopes based on the $K$-capped subset were still significantly larger than zero in HCS $(Z=-4.40, p<0.001)$ and now also passed the significance threshold in PSZ $(Z=-2.03, p=0.042)$, but they were still significantly smaller in PSZ than in HCS $(U=421.0$, $p=0.004)$. This demonstrates that the group difference in $K$-BOLD slope was not secondary to the difference in the ranges of $K$ values.

Figure 7 shows the average BOLD signal at each set size within this region. As expected, the activation pattern across set sizes mirrored the pattern seen with $K$ (Fig. 2). However, the largest group difference in BOLD signal was apparent at set size 1, at which average PPC activity was decreased below baseline in HCS but was increased above baseline in PSZ. This suggests that a failure to reduce BOLD activity at set size 1 may contribute to the shallower $K$-BOLD slope in PSZ. To test this, we computed Spearman correlations between the BOLD signal at set size 1 and the slope of the K-BOLD function and found a significant negative correlation in both groups (HCS: $r=-0.50, p=0.002$; PSZ: $r=-0.42, p=0.009$ ). We computed the same correlation for set size 4 (the set size with the maximum average BOLD signal and $K$ values in both groups) and found only positive trends (HCS: $r=0.32, p=0.057$; PSZ: $r=0.22, p<0.198)$. Thus, the steepness of the $K$-BOLD slope was reflective of the propensity to limit PPC activation when WM storage demands were minimal at least as much as the propensity to activate PPC with greater WM storage.

\section{Relationship with cognition}

To test whether left PPC (Fig. 5) signal modulation with the number of items currently stored in WM $(K)$ was related to WM capacity $\left(K_{\max }\right)$, we correlated the $K$-BOLD slope coefficient with $K$ at set size 4 . $K$ at set size 4 is the closest task-derived estimate of $K_{\max }$ because it is least limited by the number of items presented at small set sizes or by selection demands at large set sizes. Given that $K$-related BOLD signal at set size 4 contributed to defining the left PPC cluster and slope coefficient, we computed partial correlations controlling for the average regional BOLD signal at set size 4 , thereby likely underestimating the correlation but alleviating concerns of bias due to "double-dipping" (Kriegeskorte et al., 2009). Significant partial correlations were observed in both $\operatorname{HCS}\left(R_{(34)}=0.41, p=0.014\right)$ and PSZ $\left(R_{(34)}=0.47, p=0.004\right)$.

To test whether the degree of $K$-dependent signal modulation in this left PPC region was predictive of broad cognitive abilities, we correlated the single-participant $K$-BOLD slope coefficients with the MCCB composite score (Fig. 8). Spearman correlations were significant in both $\mathrm{HCS}\left(R_{(33)}=0.47, p=0.006\right)$ and PSZ $\left(R_{(37)}=0.38, p=0.021\right)$. We also performed exploratory correlations between the K-BOLD slope and the seven MCCB subdomains, and we found that only the WM domain displayed significant correlations with the slope coefficient in both groups $\left(\mathrm{HCS}: R_{(33)}=0.43, p=0.01\right.$; PSZ: $R_{(37)}=0.41, p=0.012$ ), although other correlations were significant in the one or the other group (Table 4). However, these exploratory analyses did not control for multiple comparisons, so caution should be used in interpreting the pattern of statistical significance.

To test the extent to which $K$-dependent signal change in left PPC may explain the large group difference in the MCCB composite (Table 1), we ran an ANCOVA model with diagnostic group as the independent variable and MCCB composite score as the dependent variable. Next, we added the K-BOLD slope coefficient as a covariate to determine the amount of between-group variance that could be accounted for by the coefficient. The slope coefficient was a significant covariate $\left(F_{(1,67)}=13.6, p<0.001\right)$. Diagnostic group was significant at $p<0.001$ in both models; however, including the slope coefficient as a covariate resulted in a $43.4 \%$ reduction in the variance explained by the group factor. Thus, although causality cannot be established from these results, $>40 \%$ of the schizophrenia-related broad cognitive deficit measured by the MCCB can be statistically accounted for by a lack of PPC signal modulation with current WM content.

\section{Relationship with medication}

To test whether the K-BOLD slope coefficient, as the main quantitative outcome measure, may be related to psychotropic medication use by PSZ, antipsychotic medications were converted to daily chlorpromazine-equivalent doses according to Andreasen 

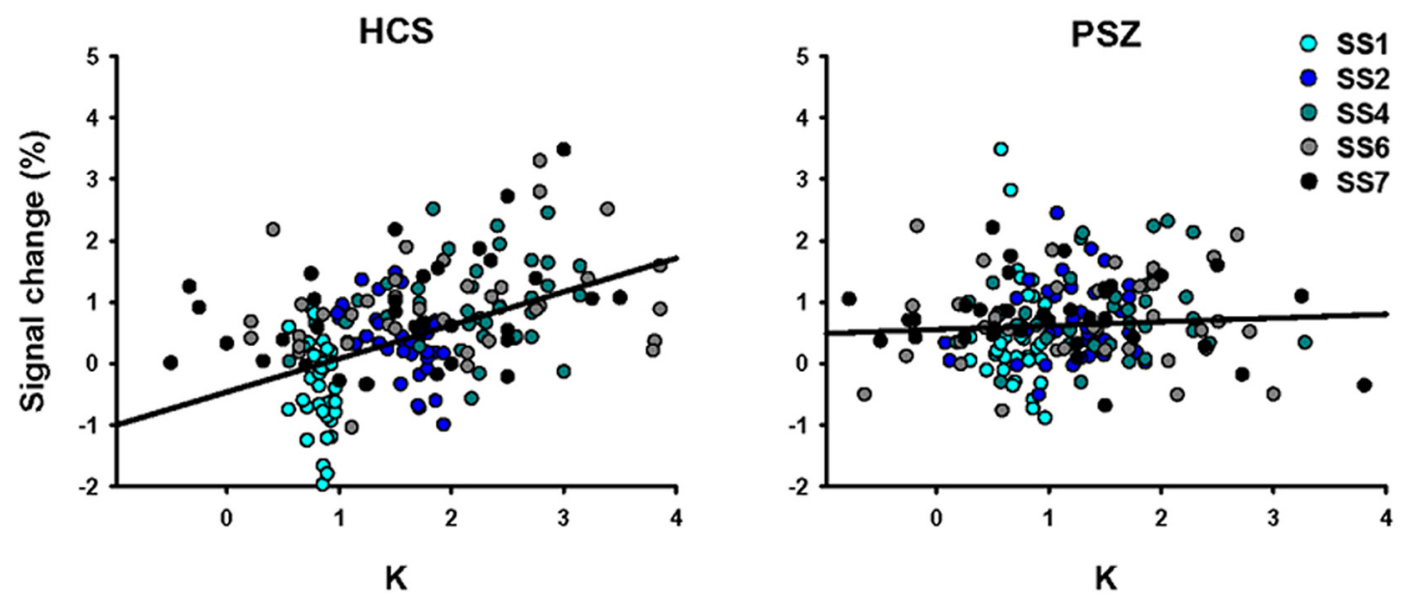

Figure 6. Differential K-BOLD associations in healthy control subjects (HCS) and participants with schizophrenia (PSZ). Scatter plots represent the relationship between Kand activation in the left PPC region displayed in Figure 5 and listed in Table 3, separately for HCS and PSZ. Each participant contributes five data points to the graph, one at each set size (SS).

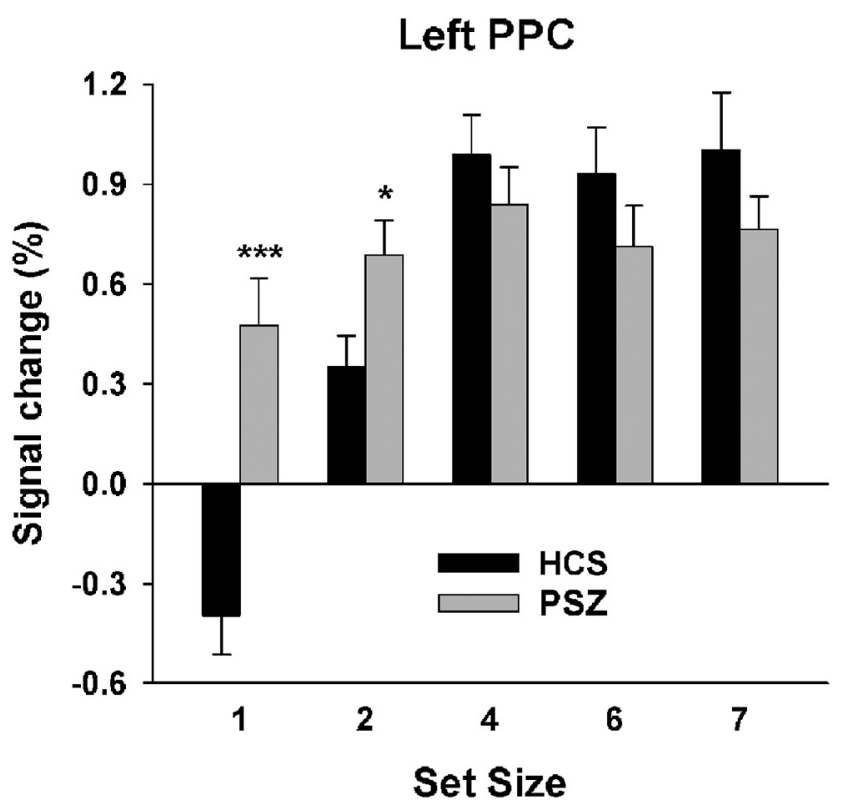

Figure 7. Left posterior parietal cortex (PPC) activation by set size. Average ( \pm SEM) BOLD activity at each set size in the region displaying a $K \times$ group interaction (Fig. 5; Table 3) for healthy control subjects (HCS) and participants with schizophrenia (PSZ). Independent-samples $t$ test comparing $\mathrm{HCS}$ and PSZ: ${ }^{*} p<0.05 ;{ }^{* * *} p<0.001$.

et al. (2010) and correlated with slope values. The Spearman correlation was not significant $\left(R_{(37)}=-0.17, p>0.3\right)$. Furthermore, the slope coefficient did not differ between PSZ who did or did not use antidepressant medication $(U=139.0, p>0.3)$, or between PSZ who did or did not use anxiolytic medication $(U=$ $146, p>0.7)$.

\section{Discussion}

The present study used a performance-based estimate of the number of items stored in WM $(K)$ to identify neuroanatomical correlates of WM storage deficits in PSZ. WM storage capacity is substantially reduced and strongly correlated with broader cognitive performance in PSZ (e.g., Johnson et al., 2013). Thus, the aim was to address the neural basis of this impairment using methods designed to emphasize storage and minimize demands on manipulation and rehearsal. Activity in posterior parietal and occipital regions varied in a $K$-dependent manner across groups, regions very similar to those identified by Todd and Marois $(2004,2005)$ with comparable methodology. As in these previous studies, there was no sign of PFC involvement in WM storage. This is in sharp contrast to studies using WM paradigms requiring manipulation or active prioritization of the stored material or allowing for active rehearsal (Manoach, 2003; e.g., Callicott et al., 2003; Glahn et al., 2005; Van Snellenberg et al., 2006).

The main finding of the present investigation was that PSZ displayed less $K$-dependent modulation of activity in a left PPC region, including SPL, IPL, and IPS. Despite the correlative nature of this finding, there are reasons to believe that a lack of flexible adaptability of neuronal activity in PPC with the number items stored in WM may indeed be a central mechanism underlying WM storage deficits in schizophrenia:

First, the combination of experimental design and analytic approach rules out the alternative explanation that the lack of differential PPC modulation in PSZ was a mere reflection of reduced WM storage engagement. A shallow slope of the association between $K$ and PPC signal does not reflect low $K$, but rather less change in PPC signal with change in $K$. A lower average $K$ does not automatically reduce the degree of PPC signal change per unit of change in $K$. Moreover, the shallower $K$-BOLD slope in PSZ than in HCS was not a result of a limited range of $K$ values in PSZ: slopes were shallower in PSZ than HCS, even when limiting the analysis to conditions in which $K$ values were no larger than 2 , a range in which $K$-related variance was matched between groups.

Second, individual differences in slope were not just the result of an inability of PSZ to recruit the PPC with more items in WM. Indeed, more robust associations were found between slope coefficients and activity at set size 1 than activity at set size 4 , although both ends clearly contributed (for a similar pattern of ERP results, see Leonard et al., 2013). Thus, the PPC impairment in PSZ is best described as a lack of flexible adjustment in activity with current WM content.

Another major finding was that the lack of $K$-dependent PPC modulation was predictive of broad cognitive functioning in both diagnostic groups and accounted for $43 \%$ of the schizophrenia-related deficit in the MCCB composite. Previous studies reported that WM storage capacity is a robust predictor of standard measures of fluid intelligence and general aptitude (Cowan et al., 2005; Fukuda et al., 2010), and reductions in WM storage capacity explained $\sim 40 \%$ of broad cognitive impairment 

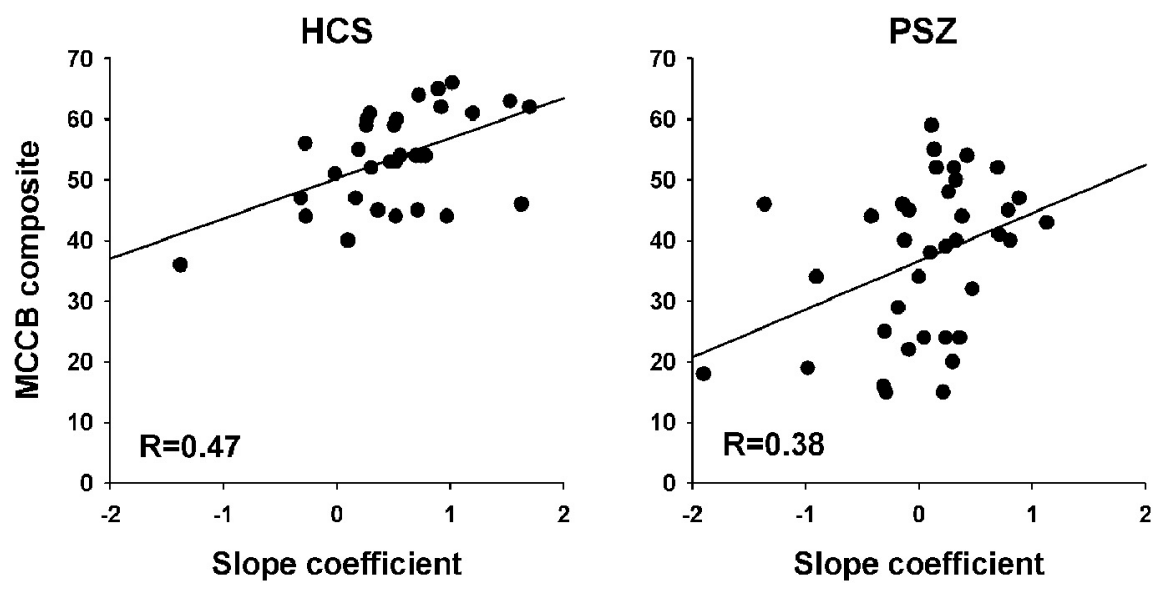

Figure 8. Slope-MCCB correlations. Relationship between the magnitude of $K$-dependent signal change in left PPC (Fig. 5; Table 3) as represented by the slope coefficient, and the MCCB composite score, in HCS and PSZ.

Table 4. Spearman rho and significance levels for correlations of the K-BOLD slope coefficient with the MCCB composite score and subscales

\begin{tabular}{lll}
\hline & $\mathrm{HCS}(N=33)^{a}$ & $\mathrm{PSZ}(N=37)$ \\
\hline MCCB composite & $R=0.47, p=0.006$ & $R=0.38, p=0.021$ \\
Processing speed & $R=0.33, p=0.059$ & $R=0.44, p=0.006$ \\
Attention/vigilance & $R=0.39, p=0.027$ & $R=0.26, p=0.115$ \\
Working memory & $R=0.44, p=0.010$ & $R=0.41, p=0.012$ \\
Verbal learning & $R=0.44, p=0.018$ & $R=0.11, p=0.501$ \\
Visual learning & $R=0.17, p=0.347$ & $R=0.34, p=0.043$ \\
Reasoning/problem solving & $R=0.09, p=0.631$ & $R=0.36, p=0.029$ \\
Social cognition & $R=-0.03, p=0.850$ & $R=0.17, p=0.318$ \\
\hline
\end{tabular}

${ }^{a}$ MCCB data missing for 4 HCS.

in PSZ (Johnson et al., 2013). The present finding points to a neural correlate for this potential core cognitive deficit, explaining a nearly identical percentage of schizophrenia-related impairment in a measure of broad cognitive functioning that was independent of our behavioral measure of WM storage. Thus, while understudied in this context relative to PFC, PPC dysfunction is likely to be of central significance for cognitive deficits associated with schizophrenia. The present study did not test a double-dissociation with paradigms challenging executive control aspects of WM; but when combined with prior research, our findings suggest that PFC and PPC are the substrates of qualitatively distinct core functional impairments in schizophrenia, with a PFC locus for impaired executive control of WM and a PPC locus for reduced storage capacity. This may be true also in other clinical populations marked by WM impairment, despite different underlying neuropathology (e.g., Stopford et al., 2012).

The present study does not weigh in on the debate over whether WM representations are actually stored in PPC or whether this area implements attentional mechanisms that impact the storage of information within sensory cortex (Postle, 2006; Xu and Chun, 2006; Emrich et al., 2013; Xu, 2017). The two views would lend different narratives to the present finding. A lack of flexible adjustment in PPC activity with current WM content could reflect a defective storage mechanism. On the other hand, the finding may reflect a lack of flexible adjustment of the amount of attentional resources allocated to representations stored in visual cortex. According to this view, item representations per se may not be impaired, given that a $K \times$ group interaction was not identified in visual cortex despite its sensitivity to the $K$ regressor. Instead, insufficient attentional resources may be allocated to larger numbers of representations and an oversupply to smaller numbers (see overactivation in PSZ at set sizes 1 and 2). Conclusive evidence supporting either view would require additional research.

While the task paradigm and analytical approach (using $K$ as regressor of interest) clearly isolated activity related to WM storage (as opposed to manipulation), the present study was not designed to dissociate encoding-related from maintenanceand retrieval-related activity. The long retention intervals necessary to do so would likely engage long-term memory and medial temporal lobe-mediated memory systems (Jeneson et al., 2012). An ERP study, whose paradigm and timing parameters closely resembled those used here, found that reductions in a $K$-related posterior ERP in PSZ began during encoding and continued throughout the $800 \mathrm{~ms}$ maintenance period (Leonard et al., 2013). Results by Todd and Marois (2004), using an approach similar to ours but adding a substudy with longer retention intervals, suggested PPC involvement in both encoding and maintenance, but not retrieval. Using a delayed recognition task with sequentially presented abstract shape stimuli and a 12 s retention interval, Linden et al. (2003) found inverted U-shaped IPS activation with set size mostly during encoding and the early parts of the maintenance period, but not retrieval. Using the same paradigm in adolescents with schizophrenia, Bittner et al. (2015) observed set size-dependent hypoactivation of frontal, parietal, and temporal regions predominantly during encoding and early in the retention interval, but not during retrieval. Consistent with these findings, retrieval-related activity in our study was accounted for by a separate regressor of no interest and thus had little or no contribution to the observed signal.

Regressing for activity related to the number of items actually represented in WM, instead of the number of items on display, also circumvents performance confounds. fMRI studies comparing cognitive processes between diagnostic groups face the dilemma that tasks need to challenge the deficits under study, but the resulting performance difference between group creates an unequal engagement of these processes (Callicott et al., 2003; Manoach, 2003; Van Snellenberg et al., 2006). Thus, activation differences may reflect a mere lack of engagement by PSZ, and not a mechanism underlying the performance deficit. Using a delayed match-to-sample task, Anticevic et al. (2013) approximated performance between groups by making the two to-beencoded stimuli more dissimilar for PSZ than for HCS. Several PFC regions displayed hypoactivation in PSZ; no effect was found in PPC. However, given the long encoding (4.4 s) and delay periods (15.4 s), differences in PFC recruitment may have pertained to task set maintenance and prevention of proactive interference, which impacts performance of WM paradigms with long encoding and delay periods (Hartshorne, 2008; Makovski and Jiang, 2008) but not the standard change detection task used here (Lin and Luck, 2012). In addition, the lower perceptual demands for PSZ than for HCS in the Anticevic et al. (2013) study may have reduced the need for complex PFC-mediated encoding and maintenance strategies. Results more compatible with the present investigation were obtained in a small- $N$ study using a color change detection task similar to that used here, with set sizes 1, 2, and 4 (Hahn et al., 2017). Approximately equal performance 
between HCS and PSZ was achieved by extensive task training before fMRI scanning. Under these conditions, task-positive, and, most prominently, PPC regions varied less as a function of set size in PSZ due to over-recruitment at set sizes 1 and 2.

Although we did not assess the pathophysiological underpinnings of the blunted PPC adjustment with current WM content, some speculation may be warranted on the basis of the literature on neuronal oscillation abnormalities in PSZ (Uhlhaas and Singer, 2010). Using a neural network model, Raffone and Wolters (2001) demonstrated that WM storage limits could potentially be explained by a balance between synchronization mechanisms maintaining neural assemblies in a coherent oscillatory state, and desynchronization between assemblies coding for different to-be-distinguished objects or features. The neuropathology associated with schizophrenia overlaps heavily with the neurobiology, enabling both fast and slow oscillatory activity, with negative impact on the orchestration of both local circuits and remote brain activity (Uhlhaas and Singer, 2013; PittmanPolletta et al., 2015). Thus, the reduced flexible moderation of WM storage-related processes in PPC may be the local expression of globally deficient neuronal synchronization mechanisms.

In conclusion, by using the task-derived number of items currently stored in WM $(K)$ as a regressor, regions of PPC and occipital cortex were identified as being involved in WM storage functions, as previously observed in young healthy volunteers using similar methodology. PSZ displayed weaker $K$-dependent modulation of activity in left PPC, an effect that could not be explained by a narrower range of $K$ values. $K$-dependent PPC modulation correlated robustly with broad cognitive abilities and was able to explain $43 \%$ of the schizophrenia-related deficit therein. We conclude that PPC dysfunction is central to WM storage deficits in PSZ, and to cognitive deficits associated with schizophrenia on a broader scale.

\section{References}

Andreasen NC (1984) The Scale for the Assessment of Negative Symptoms (SANS). Iowa City, IA: University of Iowa.

Andreasen NC, Pressler M, Nopoulos P, Miller D, Ho BC (2010) Antipsychotic dose equivalents and dose-years: a standardized method for comparing exposure to different drugs. Biol Psychiatry 67:255-262. CrossRef Medline

Anticevic A, Repovs G, Barch DM (2013) Working memory encoding and maintenance deficits in schizophrenia: neural evidence for activation and deactivation abnormalities. Schizophr Bull 39:168-178. CrossRef Medline

Baddeley AD (2007) Working memory, thought, and action. New York: Oxford UP.

Barch DM, Ceaser A (2012) Cognition in schizophrenia: core psychological and neural mechanisms. Trends Cogn Sci 16:27-34. CrossRef Medline

Barch DM, Moore H, Nee DE, Manoach DS, Luck SJ (2012) CNTRICS imaging biomarkers selection: working memory. Schizophr Bull 38:4352. CrossRef Medline

Bittner RA, Linden DE, Roebroeck A, Härtling F, Rotarska-Jagiela A, Maurer K, Goebel R, Singer W, Haenschel C (2015) The when and where of working memory dysfunction in early-onset schizophrenia-A functional magnetic resonance imaging study. Cereb Cortex 25:2494-2506. CrossRef Medline

Callicott JH, Mattay VS, Verchinski BA, Marenco S, Egan MF, Weinberger DR (2003) Complexity of prefrontal cortical dysfunction in schizophrenia: more than up or down. Am J Psychiatry 160:2209-2215. CrossRef Medline

Cowan N (2001) The magical number 4 in short-term memory: a reconsideration of mental storage capacity. Behav Brain Sci 24:87-114, discussion 114-185. Medline

Cowan N (2017) The many faces of working memory and short-term storage. Psychon Bull Rev 24:1158-1170. CrossRef Medline

Cowan N, Elliott EM, Scott Saults J, Morey CC, Mattox S, Hismjatullina A,
Conway AR (2005) On the capacity of attention: its estimation and its role in working memory and cognitive aptitudes. Cogn Psychol 51:42100. CrossRef Medline

Cox RW (1996) AFNI: software for analysis and visualization of functional magnetic resonance neuroimages. Comput Biomed Res 29:162-173.

Curtis CE, D'Esposito M (2003) Persistent activity in the prefrontal cortex during working memory. Trends Cogn Sci 7:415-423. CrossRef Medline

Edin F, Klingberg T, Johansson P, McNab F, Tegnér J, Compte A (2009) Mechanism for top-down control of working memory capacity. Proc Natl Acad Sci U S A 106:6802-6807. CrossRef Medline

Emrich SM, Riggall AC, Larocque JJ, Postle BR (2013) Distributed patterns of activity in sensory cortex reflect the precision of multiple items maintained in visual short-term memory. J Neurosci 33:6516-6523. CrossRef Medline

Engle RW, Tuholski SW, Laughlin JE, Conway AR (1999) Working memory, short-term memory, and general fluid intelligence: a latent-variable approach. J Exp Psychol Gen 128:309-331. CrossRef Medline

Erickson MA, Hahn B, Leonard CJ, Robinson B, Gray B, Luck SJ, Gold J (2015) Impaired working memory capacity is not caused by failures of selective attention in schizophrenia. Schizophr Bull 41:366-373. CrossRef Medline

Fukuda K, Vogel E, Mayr U, Awh E (2010) Quantity, not quality: the relationship between fluid intelligence and working memory capacity. Psychon Bull Rev 17:673-679. CrossRef Medline

Glahn DC, Ragland JD, Abramoff A, Barrett J, Laird AR, Bearden CE, Velligan DI (2005) Beyond hypofrontality: a quantitative meta-analysis of functional neuroimaging studies of working memory in schizophrenia. Hum Brain Mapp 25:60-69. CrossRef Medline

Gold JM, Hahn B, Zhang WW, Robinson BM, Kappenman ES, Beck VM, Luck SJ (2010) Reduced capacity but spared precision and maintenance of working memory representations in schizophrenia. Arch Gen Psychiatry 67:570-577. CrossRef Medline

Hahn B, Harvey AN, Gold JM, Ross TJ, Stein EA (2017) Load-dependent hyperdeactivation of the default mode network in people with schizophrenia. Schizophr Res 185:190-196. CrossRef Medline

Hartshorne JK (2008) Visual working memory capacity and proactive interference. PLoS One 3:e2716. CrossRef Medline

Hawk AB, Carpenter WT Jr, Strauss JS (1975) Diagnostic criteria and fiveyear outcome in schizophrenia: a report from the international pilot study of schizophrenia. Arch Gen Psychiatry 32:343-347. CrossRef Medline

Heaton RK, Gladsjo JA, Palmer BW, Kuck J, Marcotte TD, Jeste DV (2001) Stability and course of neuropsychological deficits in schizophrenia. Arch Gen Psychiatry 58:24-32. CrossRef Medline

Jaeger J, Berns SM, Czobor P (2003) The multidimensional scale of independent functioning: a new instrument for measuring functional disability in psychiatric populations. Schizophr Bull 29:153-168. CrossRef Medline

Jeneson A, Wixted JT, Hopkins RO, Squire LR (2012) Visual working memory capacity and the medial temporal lobe. J Neurosci 32:3584-3589. CrossRef Medline

Johnson MK, McMahon RP, Robinson BM, Harvey AN, Hahn B, Leonard CJ, Luck SJ, Gold JM (2013) The relationship between working memory capacity and broad measures of cognitive ability in healthy adults and people with schizophrenia. Neuropsychology 27:220-229. CrossRef Medline

Kane MJ, Engle RW (2000) Working-memory capacity, proactive interference, and divided attention: limits on long-term memory retrieval. J Exp Psychol Learn Mem Cogn 26:336-358. CrossRef Medline

Kirkpatrick B, Strauss GP, Nguyen L, Fischer BA, Daniel DG, Cienfuegos A, Marder SR (2011) The brief negative symptom scale: psychometric properties. Schizophr Bull 37:300-305. CrossRef Medline

Kriegeskorte N, Simmons WK, Bellgowan PS, Baker CI (2009) Circular analysis in systems neuroscience: the dangers of double dipping. Nat Neurosci 12:535-540. CrossRef Medline

Lee J, Park S (2005) Working memory impairments in schizophrenia: a meta-analysis. J Abnorm Psychol 114:599-611. CrossRef Medline

Leonard CJ, Kaiser ST, Robinson BM, Kappenman ES, Hahn B, Gold JM, Luck SJ (2013) Toward the neural mechanisms of reduced working memory capacity in schizophrenia. Cereb Cortex 23:1582-1592. CrossRef Medline

Lin PH, Luck SJ (2012) Proactive interference does not meaningfully distort 
visual working memory capacity estimates in the canonical change detection task. Front Psychol 3:Article 42.

Linden DE (2007) The working memory networks of the human brain. Neuroscientist 13:257-267. CrossRef Medline

Linden DE, Bittner RA, Muckli L, Waltz JA, Kriegeskorte N, Goebel R, Singer W, Munk MH (2003) Cortical capacity constraints for visual working memory: dissociation of fMRI load effects in a fronto-parietal network. Neuroimage 20:1518-1530. CrossRef Medline

Luck SJ, Vogel EK (1997) The capacity of visual working memory for features and conjunctions. Nature 390:279-281. CrossRef Medline

Lustig C, May CP, Hasher L (2001) Working memory span and the role of proactive interference. J Exp Psychol Gen 130:199-207. CrossRef Medline

Makovski T, Jiang YV (2008) Proactive interference from items previously stored in visual working memory. Mem Cognit 36:43-52. CrossRef Medline

Manoach DS (2003) Prefrontal cortex dysfunction during working memory performance in schizophrenia: reconciling discrepant findings. Schizophr Res 60:285-298. CrossRef Medline

McNab F, Klingberg T (2008) Prefrontal cortex and basal ganglia control access to working memory. Nat Neurosci 11:103-107. CrossRef Medline

Minamoto T, Yaoi K, Osaka M, Osaka N (2015) The rostral prefrontal cortex underlies individual differences in working memory capacity: an approach from the hierarchical model of the cognitive control. Cortex 71: 277-290. CrossRef Medline

Mitchell DJ, Cusack R (2008) Flexible, capacity-limited activity of posterior parietal cortex in perceptual as well as visual short-term memory tasks. Cereb Cortex 18:1788-1798. CrossRef Medline

Nuechterlein KH, Green MF (2006) MATRICS Consensus Cognitive Battery, Manual. Los Angeles: MATRICS Assessment.

Overall J, Gorman D (1962) The brief psychiatric rating scale. Psychol Rep 10:799-812. CrossRef

Pittman-Polletta BR, Kocsis B, Vijayan S, Whittington MA, Kopell NJ (2015) Brain rhythms connect impaired inhibition to altered cognition in schizophrenia. Biol Psychiatry 77:1020-1030. CrossRef Medline

Postle BR (2006) Working memory as an emergent property of the mind and brain. Neuroscience 139:23-38. CrossRef Medline

Postle BR, Ferrarelli F, Hamidi M, Feredoes E, Massimini M, Peterson M, Alexander A, Tononi G (2006) Repetitive transcranial magnetic stimulation dissociates working memory manipulation from retention functions in the prefrontal, but not posterior parietal, cortex. J Cogn Neurosci 18:1712-1722. CrossRef Medline

Raffone A, Wolters G (2001) A cortical mechanism for binding in visual working memory. J Cogn Neurosci 13:766-785. CrossRef Medline

Ragland JD, Laird AR, Ranganath C, Blumenfeld RS, Gonzales SM, Glahn DC (2009) Prefrontal activation deficits during episodic memory in schizophrenia. Am J Psychiatry 166:863-874. CrossRef Medline

Robitaille N, Grimault S, Jolicoeur P (2009) Bilateral parietal and contralat- eral responses during maintenance of unilaterally encoded objects in visual short-term memory: evidence from magnetoencephalography. Psychophysiology 46:1090-1099. CrossRef Medline

Rouder JN, Morey RD, Morey CC, Cowan N (2011) How to measure working memory capacity in the change detection paradigm. Psychon Bull Rev 18:324-330. CrossRef Medline

Serences JT (2016) Neural mechanisms of information storage in visual short-term memory. Vision Res 128:53-67. CrossRef Medline

Shura RD, Hurley RA, Taber KH (2016) Working memory models: insights from neuroimaging. J Neuropsychiatry Clin Neurosci 28:A4-5. CrossRef Medline

Stopford CL, Thompson JC, Neary D, Richardson AM, Snowden JS (2012) Working memory, attention, and executive function in Alzheimer's disease and frontotemporal dementia. Cortex 48:429-446. CrossRef Medline

Talairaque J, Tournoux P (1988) Co-planar stereotaxic atlas of the human brain. New York: Thieme.

Todd JJ, Marois R (2004) Capacity limit of visual short-term memory in human posterior parietal cortex. Nature 428:751-754. CrossRef Medline

Todd JJ, Marois R (2005) Posterior parietal cortex activity predicts individual differences in visual short-term memory capacity. Cogn Affect Behav Neurosci 5:144-155. CrossRef Medline

Uhlhaas PJ, Singer W (2010) Abnormal neural oscillations and synchrony in schizophrenia. Nat Rev Neurosci 11:100-113. CrossRef Medline

Uhlhaas PJ, Singer W (2013) High-frequency oscillations and the neurobiology of schizophrenia. Dialogues Clin Neurosci 15:301-313. Medline

Van Snellenberg JX, Torres IJ, Thornton AE (2006) Functional neuroimaging of working memory in schizophrenia: task performance as a moderating variable. Neuropsychology 20:497-510. CrossRef Medline

Vogel EK, Machizawa MG (2004) Neural activity predicts individual differences in visual working memory capacity. Nature 428:748-751. CrossRef Medline

Vogel EK, Woodman GF, Luck SJ (2001) Storage of features, conjunctions and objects in visual working memory. J Exp Psychol Hum Percept Perform 27:92-114. CrossRef Medline

Wechsler D (2001) Wechsler Test of Adult Reading (WTAR). San Antonio: The Psychological Corporation.

Wechsler D (2011) Wechsler Abbreviated Scale of Intelligence, Ed 2 (WASIII). San Antonio: NCS Pearson.

Wilkinson GS, Robertson GJ (2006) Wide Range Achievement Test (WRAT), Ed 4. Lutz, FL: Psychological Assessment Resources.

Xu Y (2017) Reevaluating the sensory account of visual working memory storage. Trends Cogn Sci 21:794-815. CrossRef Medline

Xu Y, Chun MM (2006) Dissociable neural mechanisms supporting visual short-term memory for objects. Nature 440:91-95. CrossRef Medline

Yang S, Ross TJ, Zhang Y, Stein EA, Yang Y (2005) Head motion suppression using real-time feedback of motion information and its effects on task performance in fMRI. Neuroimage 27(1):153-162. 